\title{
NEUROCIÊNCIAS E PSICANÁLISE: HÁ POSSIBILIDADE DE ARTICULAÇÃO?
}

\author{
Bianca Maria Sanches Faveret*
}

\section{RESUMO}

Existe uma proposta contemporânea de promover o trabalho interdisciplinar entre os campos da psicanálise e das neurociências, visando favorecer a integração entre ambas. Neste artigo, examino criticamente a questão de haver ou não uma possibilidade mínima de articulação entre esses domínios de conhecimento, a partir dos pressupostos epistemológicos que servem de base a cada um deles. Tal reflexão envolve tanto a minha perspectiva de psicanalista quanto o instrumental teórico que nos é oferecido por uma visão pragmática da ciência, a qual tem se desdobrado numa ampla literatura de filosofia/ sociologia das ciências naturais nas últimas décadas.

Palavras-chave: psicanálise, neurociências, ciência, objetivismo, paradigmas

\section{Abstract}

NEUROSCIENCES AND PSYCHOANALYSIS: IS THERE ANY POSSIBILITY OF ARTICULATION?

There is a contemporary proposal to increase the interdisciplinary work between the psychoanalysis and the neuroscience fields, wich purpose is to facilitate the integration of both of them. In this paper I examine critically the question about a minimum possibility of articulation between these domains of knowledge, and my starting point are the epistemological presuppositions that are in their specific bases.

These thoughts encompass so my psychoanalyst's perspectives like the theorethical instrumental of a pragmatic perspective about science, wich have been unfolded in a vast literature about philosophy/sociology of natural sciences in the last decades.

Keywords: psychoanalysis, neurosciences, science, objectivism, paradigms

\footnotetext{
* Professora Adjunta da Universidade Federal de Juiz de Fora.
} 
"Não existem algoritmos neutros para a escolha de uma teoria".

Thomas S. Kuhn (1962/1990: 246)

A International Neuro-Psychoanalysis Society foi fundada em Londres, em julho de 2000, para promover o trabalho interdisciplinar entre os campos da psicanálise e da neurociência. Publica Neuro-psychoanalysis, revista que procura favorecer a integração entre a psicanálise e a neurociência. Os editores entendem que, apesar de a psicanálise e a neurociência terem abordado a tarefa de compreender os fenômenos/transtornos mentais a partir de perspectivas radicalmente diferentes, teria se tornado muito evidente, nos últimos anos, a unidade dos propósitos subjacentes a ambos os campos, pois, quando os neurocientistas começaram a investigar as perturbações do funcionamento mental - o que, tradicionalmente, era tarefa própria aos psicanalistas -, teria acontecido uma explosão de novos insights sobre problemas que seriam de interesse vital para a psicanálise, insights que, entretanto, ainda não teriam sido conciliados com as teorias e modelos psicanalíticos existentes. Por outro lado, alegam que os neurocientistas, pela primeira vez lidando com os problemas complexos da subjetividade humana, teriam muito a aprender com mais de um século de pesquisa psicanalítica.

O corpo editorial desta revista traz nomes internacionalmente conhecidos: neurocientistas - como Eric Kandel (prêmio Nobel de fisiologia e medicina em 2000), Joseph LeDoux, Antonio Damásio, Oliver Sacks, Karl Pribam, dentre outros - e psicanalistas - como, por exemplo, André Green, Daniel Widlocher e Otto Kernberg. Eles têm realizado conferências e congressos, inclusive houve um congresso realizado no Rio de Janeiro, em julho de 2005.

Como psicanalista, e afinada com a contribuição de Lacan, tal proposta de aproximação/integração entre a psicanálise e a neurociência suscitou-me certas considerações. Em primeiro lugar, a proposta deve ser a de se pensar, primeiramente, se há ou não possibilidade de articulação entre esses campos, dadas as diferentes perspectivas epistemológicas adotadas em cada um deles, e neste sentido tenho desenvolvido algumas reflexões (Faveret, 1996a; 1996b; 1997a; 1997b; 1997c; 2000; 2002; 2003).

A maioria dos que defendem a integração entre os campos entende que a neurociência poderia ser muito útil à psicanálise para lhe proporcionar a validação objetiva de seus construtos, da qual a psicanálise seria carente. Argumenta-se que este tipo de validação facilitaria à psicanálise sair de seus círculos tautológicos, tornaria os psicanalistas mais neutros e imparciais, permitindo-lhes fugir dos ar- 
gumentos baseados na força da autoridade e impedindo-os de resvalar para o lamaçal das meras crenças e opiniōes infundadas (no qual, até então, eles se moveriam).

Tal proposta já revela a perspectiva de que partem, pois demonstram possuir uma concepção objetivista de ciência, compreendendo a atividade científica como orientada por um ideal de aproximação da verdade, envolvendo uma noção de verdade que se vincula à própria realidade: haveria verdade quando as teorias estabelecessem uma relação de correspondência com os "dados" da realidade. Mas não existe, nos dias de hoje, apenas esta concepção do que seja o conhecimento científico.

De fato, nas últimas décadas, uma visão pragmática da ciência vem sendo tematizada, de forma diversificada e bastante complexa, por reflexóes na área da filosofia e sociologia das ciências naturais que congregam autores oriundos dos mais diferentes campos. Esta área de discussões tem, como marco histórico, a redefinição de Thomas Kuhn (1962/1990) para as teorias científicas em termos de paradigmas. Como apontou mais recentemente Barnes (1982), antes de Kuhn as variáveis socioculturais envolvidas na atividade científica eram consideradas na medida em que podiam servir para dar sentido aos pensamentos e às ações de indivíduos particulares, ou seja, o foco do interesse era o individual. $\mathrm{O}$ interesse pelo contexto sociocultural servia apenas como uma moldura para destacar o comportamento racional do cientista, assim como se pode fazer referência a um contexto geográfico para ressaltar que o comportamento de um navegador é racional. Também se atribuíam aos conceitos, crenças e princípios científicos um potencial imanente (de modo a pensá-los como entidades autônomas capazes de influenciar a "mente" dos cientistas) e a mudança na cultura científica era vista como uma espécie de desdobramento de implicações inerentes às idéias. Depois de Kuhn, o sociocultural deixou de ser pensado apenas como o setting da pesquisa, e a própria pesquisa científica passou a ser vista como uma elaboração sociocultural.

Reconhecendo que sua redefinição se filiava ao pensamento de Wittgenstein e de Quine, Kuhn (1962/1990) propôs uma visão des-naturalizada de ciência, enfatizando, dentre outras coisas, que as comunidades científicas implementam treinamentos nos quais se aprende a identificar determinados padróes de similaridade que conduzem a diversos recortes ontológicos. As diferentes ontologias, oriundas dos diversos recortes, definem então entidades diferentes, de modo que a percepção/observação dos cientistas não é natural, mas aprendida. Aprende-se a perceber e a observar através de processos de socialização, e a prática da vida científica, como qualquer outra forma de vida social, exige que os indivíduos/cientistas consensualmente compartilhem os mesmos padrões de percepção e regras de observação. 
Desta forma, os diversos paradigmas envolvem diferentes compromissos ontológicos, pois definem diferentes entidades e determinam diferentes questôes, estabelecendo quais problemas e quais métodos são legítimos. Eles envolvem modos específicos de percepção e de conceitualização da realidade, formas particulares de inferência, de analogia e de estabelecimento de padróes para julgamento e avaliação no curso da pesquisa científica.

Conseqüentemente, não é possível achar uma justificativa racional para preferir um paradigma a outro. É o que Kuhn considera quando aborda a questão da incomensurabilidade dos paradigmas. Como ressalta Barnes (1982), não é possível provar que um deles é mais correto do que outro. Se os conceitos, teorias e procedimentos se modificam, os problemas também mudam; se os critérios de julgamento se modificam, inclusive os critérios sobre o que é um problema e o que é uma solução para um problema, então a própria percepção - que é a base da imaginação científica - fica modificada. Em resumo, assim como Wittgenstein (1953/1989) dizia que as formas de vida são incomensuráveis, assim também os paradigmas - as formas de vida científica - são incomensuráveis (Kuhn, 1962/ 1990). Se eles não podem ser comparados, a superioridade de um paradigma em relação a outro só pode ser avaliada a partir de critérios externos ao paradigma, tais como: levar a um maior grau de controle dos fenômenos da natureza, permitir certos desenvolvimentos tecnológicos, servir a determinados interesses sociais, econômicos e políticos, etc.

A discussão sobre a visão pragmática de ciência tem se desdobrado numa ampla literatura de filosofia/sociologia das ciências naturais nas últimas décadas. Os autores desta área geralmente relacionam suas investigações ao pensamento de Wittgenstein e de Kuhn, mas pode-se ver também que os trabalhos de Quine embasam diversos momentos de suas reflexões, embora este último raramente seja citado. Para uma discussão das articulações que são feitas entre estes diferentes autores, que individualmente já são objeto de múltiplas interpretações controversas, ver Coutinho (1994).

As investigaçôes desenvolvidas nesta área de reflexões continuam analisando como a produção teórica e a atividade científica dos cientistas da natureza são tão dependentes da observação dos fenômenos tidos como naturais quanto de diversos fatores macro e microsociopolíticos. A respeito de fatores macropolíticos, desenvolveram-se análises sobre como as convenções sociais, os interesses, as tradições e a busca de prestígio se articulam na produção científica. Quanto às análises mais recentes de fatores micropolíticos, estas vão desde o estudo da subcultura que existe nos laboratórios e sua articulação com a cultura mais ampla - ver Latour \& Woolgar (1997), por exemplo - até ao exame das negociaçôes que perpassam 
uma grande variedade de micromundos sociais na prática científica. Outro exemplo: a coletânea organizada por Pickering (1992), que congrega artigos de vários dos autores mais representativos dos dois tipos de análise mencionados acima, como Bloor, Collins, Fujimura, Gooding, Knorr-Cetina, Lynch, Pickering e os já mencionados Latour e Woolgar, dentre outros. Estas reflexões na área da filosofia/ sociologia da ciência - que se voltam principalmente para a prática científica nos campos das ciências naturais - servem para ressaltar que a atividade científica tem sido cada vez mais entendida como uma prática social, lingüística e política. O que me leva a reiterar que ela está sendo cada vez mais des-naturalizada e que cada vez mais o processo de construção de suas respectivas ontologias vem sendo estudado.

Embora tais reflexões tenham promovido, de fato, uma compreensão cada vez mais des-naturalizada das ciências naturais, nem por isso estas passaram a ser vistas como envolvendo apenas aspectos lingüísticos, ou seja, sócio-histórico-culturais. O não meramente lingüístico - expressão cunhada por Coutinho (1996) tem sido sempre um pressuposto dessa literatura. Pickering e Stephanides (1992), por exemplo, ao analisarem o processo de modelização na prática conceitual, tematizam explicitamente a questão das resistências e dos constrangimentos que surgem nos movimentos de extensão dos modelos. Tais movimentos não são todos eles movimentos de livre escolha dos cientistas. Assim, pensar a ciência mais dura como uma elaboração cultural não significa propor um vale-tudo simbólico/ lingüístico, como tem acontecido na filosofia pragmática das ciências sociais.

Entendendo-se a atividade científica desta forma, isto é, de que nela se procede ao recorte de diferentes ontologias, fica claro que o domínio do psíquico é um outro campo ontológico que emerge da intersecção entre o recorte das ontologias promovido pelo domínio dos paradigmas da neurociência e aquele promovido pelo domínio dos paradigmas das ciências da cultura. Disso resulta que o psíquico pode ser pensado como o locus do entrecruzamento entre estes dois principais recortes que problematizam a experiência humana.

Os defensores da aproximação entre psicanálise e neurociência invocam a afinidade demonstrada por Freud com outros campos de conhecimento, com a neurologia, a neuroanatomia, a biologia - que atualmente se abrigam no domínio crescente da neurociência - e também com o campo da termodinâmica clássica.

Como um homem vividamente interessado na vanguarda científica de seu tempo, de fato Freud atrelava suas elaborações intelectuais a toda a visão de mundo dominante na época. Como um erudito, sempre articulava o raciocínio às atividades dos mais diferentes campos culturais então existentes. As inúmeras referências às artes e à literatura mostram-no percorrendo todos os quadrantes da 
cultura, com um pensar vigoroso que varria quase todos os domínios do conhecimento. Ele discutia, questionava e articulava perspectivas tão diversas como as da arqueologia, da filosofia - Platão, Kant, Hartmann, Schopenhauer, etc -, a antropologia de Frazer, a sociologia de Le Bon, a psicologia de Wundt, àquelas mais duras das ciências naturais, pois, além da termodinâmica, seu pensar relacionavase com as contribuições da física da eletricidade, da química de Lavoisier e com outras elaboraçôes mais exatamente médicas como as da fisiologia de Claude Bernard, a neurofisiologia de Jackson, Meynert e Wernicke, a psiquiatria em geral, e com a biologia de Lamarck, Darwin, Haeckel, Spencer e Weismann.

Ou seja, o pensar freudiano articulou-se, com certeza, aos campos hoje compreendidos como do domínio da neurociência, mas não somente a eles. Para uma análise mais abrangente da inserção de Freud na cultura de sua época e, mais especificamente, nas teorias das ciências humanas e sociais, pode-se consultar o estudo feito por Rieff (1979) a este respeito.

Eles também apontam que Freud iniciou sua carreira como neuroanatomista e neurologista e afirmam que o Projeto para uma psicologia cientifica, de 1895 , teria se baseado nos conhecimentos neurocientíficos ainda rudimentares da época. Parece que fazem uma grande confusão, porque, tendo-se em mente a noção de paradigmas científicos, é impossível estabelecer uma relação de similaridade entre a neurologia, neuroanatomia ou neurofisiologia da época de Freud com a neurociência de hoje. O paradigma é outro.

Dentre os argumentos dos que propõem a integração entre psicanálise e neurociência está o de que o pensar freudiano manteve até o fim a concepção de que os fenômenos mentais possuem um substrato biológico. De fato, Freud sempre considerou haver uma ancoragem do psíquico no domínio do biológico, nunca pensou o aparelho psíquico como uma entidade transcendente, desencarnada. Mas enfatizou muitíssimo, também, a ancoragem do psíquico na história do indivíduo e na história da espécie humana, na sociedade, na cultura. Esta é uma das razôes pelas quais prefiro entender, como já disse mais acima e em linguagem contemporânea, que o domínio do psíquico é um outro campo ontológico que emerge da intersecção entre o recorte das ontologias promovido pelo domínio dos paradigmas da neurociência e aquele promovido pelo domínio dos paradigmas das ciências da cultura. Como tal, é irredutível a qualquer um desses dois campos que lhe são adjacentes.

Outro argumento utilizado é retirado do Esboço de psicanálise (1938/1980), quando Freud escreve que a psicanálise, a psicologia que se ocupava do Inconsciente, "poderia assumir seu lugar entre as ciências naturais como uma ciência" (Freud, 1938/1980: 183). É preciso situar esta afirmação no contexto da época 
em que foi feita. A visão positivista/objetivista da ciência era a única visão disponível naquele momento, pois as críticas do conhecimento científico pela filosofia e pela sociologia só surgiram a partir da segunda metade do século XX. Até então, o Zeitgeist privilegiava a utilização do método experimental, somente considerando como legítima e incontestavelmente científica a atividade dos cientistas da natureza.

Certamente podemos observar em alguns momentos da elaboração intelectual de Freud a vigência de uma concepção objetivista, entretanto existem também inúmeras indicações a respeito de seu afastamento daquela visão dominante em sua época, dada a natureza da problemática por ele abordada. Mas o importante a ressaltar é que esta não é a única perspectiva sobre a atividade científica de que dispomos atualmente: há uma vasta literatura que defende uma visão de ciência enquanto produção cultural, social e historicamente determinada.

Pode-se parar para pensar um momento no quão deve ter sido difícil para a mente de Freud, educada segundo os cânones daquela concepção positivista de conhecimento, se afastar progressivamente mais e mais da neurologia, procurando estabelecer as bases para edificar um conhecimento sobre o Inconsciente, uma psicologia das profundezas... Freud sabia que se afastara muitíssimo de um pertencimento às ciências naturais, tanto que nunca desejou que o Projeto fosse publicado, engavetando-o.

Se encontramos ressonâncias do Projeto em outros construtos freudianos, sobretudo nos conceitos metapsicológicos, não precisamos entender que ele se manteve, sempre, um tanto quanto neurologista. Ao contrário, não dá no mesmo falar de energia nervosa - como Freud faz no Projeto - e de energia psíquica, como ele mais tarde a conceitua. Como a idéia do princípio de constância, de equilíbrio, da termodinâmica clássica - subentendida no Projeto - não é o mesmo que a concepção do princípio de prazer. Tampouco a idéia da entropia, do segundo princípio da termodinâmica, seria posteriormente traduzida como pulsão de morte. Não é disso que se trata, as concepções são outras, as idéias são diferentes, pois os paradigmas mudaram.

Com efeito, Freud redefiniu e ressignificou certas noções contidas no Projeto - tanto que se valeu de outros nomes -, mas a partir de uma outra perspectiva, com outros interesses, definindo outras entidades e operando outros recortes ontológicos.

Pickering \& Stephanides (1992) oferecem um ponto de vista interessante para se pensar a questão. Eles afirmam que a atividade prática dos cientistas da natureza pode ser entendida como um processo de modelização da extensão criativa dos elementos culturais existentes. Uma das propriedades-chave da 
modelização - permanentemente importante - é a da sua abertura sem fim (openendedness).

Um dado modelo pode ser estendido num número indefinido de modos; nada, dentro do próprio modelo, prediz quais seriam os escolhidos. Assim, parte do problema de lutar com a prática é o de compreender o fechamento, de compreender por que algum indivíduo ou grupo estende modelos particulares de modos particulares (Pickering \& Stephanides, 1992: 140).

Eles esclarecem também que os modelos não são estendidos isoladamente. A modelização procura produzir associaçôes, nas quais a pluralidade de elementos projetados de algum modo concordam - ou se suportam - mutuamente. Mas a realização de tais associações não é garantida a princípio, pois, como já mencionei anteriormente, resistências e constrangimentos surgem neste movimento de extensão dos modelos: o não-meramente lingüístico coloca limites à livre escolha dos cientistas.

Em outras palavras, Pickering \& Stephanides (1992) propõem que o processo de modelização pode ser decomposto em três operações mais simples e bem definidas: ponteamento (bridging), transcrição e satisfação $(\text { filling })^{1}$. Ponteamento e satisfação são movimentos livres no processo de modelização, movimentos que marcam tentativas de escolha dentro de um espaço indefinidamente aberto de extensão cultural. Já a transcrição é um movimento forçado, que interage com os outros dois e que serve para elaborar aquelas escolhas de modos que vão além do controle dos cientistas.

Utilizo-me desta argumentação porque me parece possível pensar o Projeto não como um precursor da metapsicologia, mas como uma cabeça-de-ponte lançada por Freud para conseguir a extensão do modelo da neurologia, em seu esforço para a construção de um outro campo de conhecimento.

As reflexões de Kuhn (1962/1990) vêm-me outra vez à mente para pensar as alegações dos defensores da aproximação psicanálise/neurociências, como, por exemplo, a que se refere à ausência de imparcialidade e de objetividade do analista quanto à observação do que se passa no setting. Ora, os paradigmas sempre condicionam e pré-determinam a observação dos cientistas, porque mesmo os cientistas da natureza passam por uma educação científica, na qual, volto a lembrar, aprendem a identificar determinados padrôes de similaridade que conduzem a diversos recortes ontológicos; as ontologias oriundas dos diversos recortes definem então entidades diferentes, compromissos ontológicos diferentes, o que é e o que não é um problema relevante, quais métodos e técnicas são legítimos, etc. 
Portanto, esta não é uma questão que se levante contra o campo da psicanálise, porque as teorias científicas fazem justamente isto: influem na interpretação da observação.

Quanto à crítica de que a adoção das teorias psicanalíticas torna-se uma questão de crença, imposta pela força do argumento da autoridade e da tradição, a descrição da atividade científica oferecida por Kuhn nos permite ver que, mesmo nas ciências duras, os jovens cientistas só passam a trabalhar nas pesquisas depois de passarem por períodos de familiarização com a tradição de seus campos específicos: a função dos ciclos básicos nas universidades e dos manuais científicos é exatamente esta.

Os cientistas nunca aprendem conceitos, leis e teorias de uma forma abstrata e isoladamente. Em lugar disso, esses instrumentos intelectuais são, desde o início, encontrados numa unidade histórica e pedagogicamente anterior, onde são apresentados juntamente com suas aplicaçôes e através delas (Kuhn, 1962/1990: 71).

Mas, quando um cientista maduro pode considerar como certo seu paradigma, ele não precisa mais, "nos seus trabalhos mais importantes, tentar construir seu campo de estudos começando pelos primeiros princípios e justificando o uso de cada conceito introduzido" (Kuhn, 1962/1990: 40). O cientista passará a criar sua pesquisa a partir de onde o manual a interrompe; e poderá, assim, chamar à sua argumentação a força da autoridade, passando adiante, sem mais delongas.

Como esclarece este autor,

Suas pesquisas já não serão habitualmente incorporadas a livros como Experiências... sobre a eletricidade de Franklin ou a Origem das espécies de Darwin, que eram dirigidos a todos os possíveis interessados no objeto de estudo do campo examinado. Em vez disso, aparecerão sob a forma de artigos breves, dirigidos apenas aos colegas de profissão, homens que certamente conhecem o paradigma partilhado e que demonstram ser os únicos capazes de ler os escritos a eles endereçados (Kuhn, 1962/1990: 40).

Se o terreno em que se move a neurociência é o do objetivismo, fica difícil pensar a possibilidade de sua articulação com a psicanálise. O próprio Freud já alertara muito claramente que os psicanalistas, em sua prática clínica, deveriam empregar a moeda corrente do país que estão explorando, isto é, a moeda da realidade psíquica, das fantasias inconscientes, e não a moeda da realidade externa. Assim escreveu ele: 
A característica mais estranha dos processos inconscientes (reprimidos), à qual nenhum pesquisador se pode acostumar sem o exercício de grande autodisciplina, deve-se ao seu inteiro desprezo pelo teste de realidade; eles equiparam a realidade do pensamento com a realidade externa e os desejos com sua realização - com o fato - tal como acontece automaticamente sob o domínio do antigo princípio de prazer. Daí também a dificuldade de distinguir fantasias inconscientes de lembranças que se tornaram inconscientes. Mas nunca nos devemos permitir ser levados erradamente a aplicar os padrões da realidade a estruturas psíquicas reprimidas e, talvez, por causa disso, a menosprezar a importância das fantasias na formação dos sintomas, sob o pretexto de elas não serem realidade, ou a remontar um sentimento neurótico de culpa a alguma outra fonte, por não haver provas de que qualquer crime real tenha sido cometido (Freud, 1911/1980: 285).

Reiterando, os analistas não lidam com a realidade externa, material e "objetiva”, e sim com a realidade psíquica de seus analisandos. Sendo assim, qual o interesse, para a psicanálise, de uma integração com a neurociência? Mais ainda, de que nos adiantaria tentar reencontrar todas as exigências da lógica racional no seio da fantasia? Como lembra Viderman (1990), as fantasias inconscientes não são eidos platônicos, formas rígidas, fixas e incorruptíveis inscritas para sempre num céu de inteligibilidade que a análise reencontraria ponto por ponto. Interpretar o inconsciente do sujeito não consiste em decifrar as sedimentações depositadas pela memória, ou "recompor a ordenação rompida dos traços históricos para nela ler significações oblíquas que bastará colocar na vertical para que coincidam com uma verdade" (Viderman, 1990: 151). O trabalho da análise é de mão dupla: o analista propõe a interpretação, pela qual o analisando, pela interpretação da interpretação, faz surgir verdades que não estavam em nenhuma outra parte antes de serem descobertas na situação analítica que as constituiu.

O espaço analítico - que é sobretudo um espaço de linguagem - é o terreno no qual os dados "não-reais" da percepção do analisando são remanejados, recompostos e organizados, no qual não nos limitamos a repetir formas, mas a fazê-las existir numa forma de existência que é, também, um começo. Sem se preocupar com a realidade externa, o trabalho do analista é o de ajustar e reunir esses materiais para construir um todo coerente que não reproduz uma fantasia préexistente no inconsciente do sujeito, mas fá-la existir ao dizê-la (Viderman, 1990: $151,152)$.

Por fim, é preciso lembrar que existem perspectivas diferentes no seio da própria neurociência, e pensar o interesse da contribuição de neurobiólogos 
renomados como Humberto Maturana \& Francisco Varela (1980; 1990) para o campo da psicanálise. Estes cientistas posicionaram-se contra uma visão objetivista do conhecimento humano, sustentando a idéia de que toda a objetividade deveria ser colocada entre parêntesis. Maturana, especificamente, sustenta que, de um ponto de vista interno ao próprio sistema nervoso, "em nossa experiência humana não podemos distinguir entre ilusão e o que chamamos cotidianamente [de] percepção" (Maturana, 1990: 17). Negando a existência de um ponto de referência externo, objetivo e independente do conhecimento humano para validar nossas observações, Maturana \& Varela (1990) não derrapam numa posição solipsista/ idealista porque apontam que o critério é dado pela comunidade de linguagem. "Experiências que não estão na linguagem, não são" (Maturana, idem).

\section{REFERÊNCIAS BIBLIOGRÁFICAS}

Barnes, B. (1982). T. S. Kuhn and social science. London: Macmillan Press.

Coutinho, A. R. (1994). Repensando a questão da subjetividade em uma perspectiva pragmática. Em Freire-Costa, J. (Org.). Redescriçōes da psicanálise (pp. 61-117). Rio de Janeiro: Relume-Dumará.

. (1996). Cientificidade e relevância social I: controvérsias sobre a cientificidade da psicologia e das ciências sociais. Psicologia: teoria e pesquisa, 12 (1), 23-37.

Faveret, B. M. S. (1996a). Uma contribuição da biologia contemporânea: uma filosofia do psíquico. Em Faveret, B. M. S.; Leal, C. E.; Bohadana, E. et al. Freud, o interesse científico de uma filosofia inquieta (pp. 105-132). Rio de Janeiro: Revinter.

. (1996b). O sujeito psicológico e o novo paradigma em biologia. Em PUCRio, Depto. de Psicologia (Org.). Anais do Seminário Brasileiro: A Psicologia em Contexto. Rio de Janeiro: Pontifícia Universidade Católica do Rio de Janeiro.

. (1997a). Trieb x Instinkt: uma distinção a ser refinada. Psicologia Clínica: pósgraduação e pesquisa, 8, 51-73. Rio de Janeiro: Pontifícia Universidade Católica do Rio de Janeiro.

(1997b). Psicanálise e cultura científica contemporânea. Tempo Psicanalitico, 29 (pp. 7-27). Rio de Janeiro: Sociedade de Psicanálise Iracy Doyle.

. (1997c). Psicanálise e biologia: o adoecer psíquico repensado a partir do paradigma informacional. Tese de Doutorado. Curso de Pós-graduação em Psicologia Clínica. Pontifícia Universidade Católica do Rio de Janeiro, Rio de Janeiro, RJ.

(2000). Um diálogo psicanalítico com a cultura contemporânea. Ágora: Estudos em Teoria Psicanalitica, III (1), 45-57. Rio de Janeiro: Programa de Pós-graduação em Teoria Psicanalítica, Universidade Federal do Rio de Janeiro. 
. (2002). Psychoanalysis and biology: an epistemological re-discussion. International Forum of Psychoanalysis, 2, 202-208. Hampshire, UK.

- (2003). A metáfora computacional e o reducionismo biológico: que tipo de ilusão é esta? Em Bastos, R. L. (Org.). Psicologia, microrrupturas e subjetividades (pp. $75-$ 86). Rio de Janeiro: E-Papers.

Freud, S. (1911). Formulações sobre os dois princípios do funcionamento mental. E. S. B. Rio de Janeiro: Imago, 1980.

- (1938). Esboço de psicanálise. E. S. B. Rio de Janeiro: Imago, 1980.

Kuhn, T. (1962). A estrutura das revoluçôes cientificas. São Paulo: Perspectiva, 1990.

Latour, B. \& Woolgar, S. (1997). A vida de laboratório: a produção dos fatos científicos. Rio de Janeiro: Relume-Dumará.

Maturana, H. R. (1990). Biologia de la cognicion y epistemologia. Temuco: Ed. Universidad de la Frontera.

Maturana, H. R. \& Ludewig, K. (1992). Conversaciones com Humberto Maturana: preguntas del psicoterapeuta al biólogo. Temuco: Ed. Universidad de la Frontera.

Maturana, H. R. \& Varela, F. (1980). Autopoiesis and cognition. Dordrecht: D. Reidel Publishing Company.

- (1990). El arbol del conocimiento. Santiago: Ed. Universitaria.

Pickering, A. (Ed.). (1992). Science as practice and culture. Chicago: The University of Chicago Press.

Pickering, A. \& Stephanides, A. (1992). Constructing quaternions: on the analysis of conceptual practice. Em Pickering, A. (Ed.). (1992). Science as practice and culture (pp. 139-167). Chicago: The University of Chicago Press.

Rieff, P. (1979). Freud, the mind of the moralist. Chicago: the University of Chicago Press. Viderman, S. (1990). A construção do espaço analítico. São Paulo: Escuta.

Wittgenstein, L. (1953). Investigações filosóficas. São Paulo: Nova Cultural, 1989.

\section{NOTAS}

${ }^{1}$ Satisfação no sentido matemático do termo.

Recebido em 10 de dezembro de 2005 Aceito para publicação em 16 de março de 2006 